\title{
Da expansão ao retrocesso: mudanças na Agência Brasil de 2015 a 2018
}

\author{
Akemi Nitahara Souza ${ }^{1}$ \\ Cristina Rego Monteiro da Luz²
}

\section{Resumo}

Este artigo relata as mudanças na Agência Brasil, agência pública de notícias online da Empresa Brasil de Comunicação (EBC), desde 2015. Em meio à crise política que culminou no impedimento da presidenta Dilma Rousseff, a Agência Brasil, junto com a EBC, buscava se consolidar como meio de comunicação pública. O Conselho Curador da empresa e os funcionários mobilizados pediam o aprofundamento do projeto e queriam que a EBC tivesse mais autonomia em relação ao governo federal. Ao mesmo tempo, trocas de chefias e interferências políticas mostravam o interesse do poder executivo em manter controle sobre o complexo de comunicação da $\mathrm{EBC}$, que tem seu maior alcance e relevância na Agência Brasil, site que fornece gratuitamente fotos e textos jornalístico para milhares de veículos em todo o Brasil e em outros países.

Palavras-chave: Agência Brasil. EBC. Comunicação pública.

\section{Abstract}

This article reports the changes in Agência Brasil, news website of Empresa Brasil de Comunicação (EBC), since 2015. In the middle of a political crisis that led to the impeachment of President Dilma Rousseff, Agência Brasil and EBC sought to consolidate itself as public media. The company's Board of Trustees and the mobilized employees called for a deepening of the project and wanted EBC to have more autonomy from the federal government. At the same time, changes in command positions and political interference showed the government interest in maintaining the EBC communication system, which has its major reach and public relevance in Agência Brasil, under control. Agência Brasil website provides free photos and journalistic texts for thousands of websites and newspapers throughout Brazil and other countries.

Keywords: Agência Brasil. EBC. Public media.

\section{Introdução}

\footnotetext{
1 Jornalista concursada da Empresa Brasil de Comunicação e mestranda do PPGTLCom da ECO/UFRJ. E-mail: akemi.nitahara@gmail.com.

2 Professora doutora Associada do Departamento de Expressão e Linguagens da ECOUFRJ e do PPGLTCom-UFRJ. E-mail: crmluz@globo.com.
}

Revista Pauta Geral-Estudos em Jornalismo, Ponta Grossa, vol. 6, n. 1, p. 95-111, Jan/Jun, 2019. 
Previsto na Constituição Federal de 1988, o sistema público de comunicação no Brasil ainda está em fase de compreensão por parte da sociedade e do governo, e tem sido objeto de estudos na última década. Os pesquisadores concordam ${ }^{3}$ que a comunicação pública é "um componente vital de um sistema midiático efetivamente plural, livre e independente", como colocam Eugênio Bucci, Marco Chiaretti e Ana Maria Fiorini nos Indicadores de Qualidade nas Emissoras Públicas (2012, p. 9).

Utilizaremos neste trabalho o conceito de comunicação pública indicado nessa publicação, como um elemento complementar aos atores privados, comunitários e governamentais no sistema de mídia de um país. Para tanto, os autores apontam como critérios básicos para a comunicação pública:

1) independência editorial e financeira; 2) autonomia dos órgãos de governança; 3) pluralidade, diversidade e imparcialidade da programação; 4) claro mandato de serviço público, estabelecido em documentos legais pertinentes; 5) prestação de contas (accountability) junto ao público e junto aos órgãos reguladores independentes (BUCCl, CHIARETTI e FIORINI, 2012, p. 9).

Também seguindo os Indicadores da Unesco, usaremos como definição para emissora ou veículo de mídia governamental uma estatal cujo "vínculo administrativo se dá com o Poder Executivo e esse vínculo implica subordinação, expressa ou velada" (Idem p. 22), o que ocorre principalmente por meio do financiamento via orçamento público. Isso acarreta na "interferência do governo sobre a linha editorial e o uso do serviço como forma de propaganda governamental" (Ibidem p. 16). Destacamos que emissoras governamentais são estatais e as públicas não deveriam ter, idealmente, vínculo direto com o estado, embora em muitos exemplos internacionais o financiamento seja via estado e a vinculação jurídica também, como no caso brasileiro.

No Brasil, o projeto de comunicação pública foi materializado com a criação da Empresa Brasil de Comunicação (EBC), em outubro de 2007, pela Medida Provisória 398,

\footnotetext{
3 Para aprofundar o tema, sugerimos a leitura de: AZEVEDO, Flávia; RODRIGUES, Diogo Moyses; SILVA, Sivaldo Pereira; VALENTE, Jonas et. al. Sistemas públicos de comunicação no mundo: experiências de doze países e o caso brasileiro. São Paulo: Paulus, Intervozes, 2009; MENDEL, Toby. Serviço público de radiodifusão: um estudo de direito comparado. Brasília: UNESCO, 2011; LEAL FILHO, Laurindo. A melhor TV do mundo. São Paulo: Summus, 1997; e RAMOS, Murilo Cesar et al (organizadores). Em defesa da comunicação pública. Brasília: FAC Livros, 2017.
}

Revista Pauta Geral-Estudos em Jornalismo, Ponta Grossa, vol. 6, n. 1, p. 95-111, Jan/Jun, 2019. 
convertida na Lei $n^{0} 11.652^{4}$ de 2008. A EBC incorporou os bens, serviços e funcionários da Empresa Brasileira de Comunicação (Radiobrás) e da Associação de Comunicação Educativa Roquete Pinto (Acerp). Isso incluiu as rádios Nacional e MEC; a Radioagência Nacional; as TVEs do Rio de Janeiro e do Maranhão e a TV Nacional de Brasília, que deram origem à TV Brasil; e a Agência Brasil $(A B r)$, que na época da criação da EBC já era reconhecida pela qualidade da cobertura jornalística isenta e seus conteúdos gratuitos eram reproduzidos por sites e jornais de todo o país, segundo Nitahara (2015).

A Agência Brasil tem origem na Agência Nacional (AN), órgão que foi vinculado ao Departamento de Imprensa e Propaganda (DIP), máquina de controle da imprensa na ditadura Vargas. A AN foi criada em 1937 para servir ao projeto de "integração nacional por meio da circulação doméstica de notícias" e também para "difundir os discursos do regime" (AGUIAR e LISBOA, 2016). Entre as funções da AN estava a elaboração do boletim de rádio $A$ Hora do Brasil, criado em 1938 pelo governo.

Ao longo de sua história, a AN foi vinculada a diversos órgãos de comunicação governamental, como DPDC, DNP, DNI, Gabinete Civil da Presidência da República e também ao Ministério da Justiça. Em 1979 ela é transformada em Empresa Brasileira de Notícias (EBN), pela lei $n^{\circ} 6.650^{5}$, que criou a Secretaria de Comunicação Social da Presidência da República e vinculou ao novo órgão tanto a EBC como a Radiobrás, então responsável pelas rádios e TV Nacional. Com o decreto ํㅜㅇ․ $912^{6}$ de 1988, a EBN é incorporada à Radiobrás. Porém, segundo Aguiar e Lisboa (2016), o serviço foi descontinuado nesta época, sendo recriado em 1990 no governo Fernando Collor de Mello como Agência Brasil, dentro da Radiobrás mas subordinada ao Ministério da Justiça. O objetivo era "difundir notícias governamentais e abastecer os veículos de comunicação" (AGUIAR E LISBOA, 2016), bem como elaborar o programa de rádio em cadeia nacional a Voz do Brasil, nome adotado a partir de 1962.

A mudança de foco de comunicação governamental para jornalismo público começou com a gestão de Eugênio Bucci na Radiobrás (2003-2007). Bucci é professor da Escola de Comunicações e Artes da Universidade de São Paulo e um dos principais estudiosos de comunicação pública do país. Ele relata que empreendeu na estatal uma

\footnotetext{
${ }^{4}$ http://www.planalto.gov.br/ccivil_03/_Ato2007-2010/2008/Lei/L1 1652.htm (acesso em $29 / 06 / 19)$

5 http://www.planalto.gov.br/ccivil_03/LEIS/L6650.htm (acesso em 29/06/19)

${ }_{6}^{6} \mathrm{http}$ ///www.planalto.gov.br/ccivil_03/decreto/Antigos/D96212.htm (acesso em 29/06/19)

Revista Pauta Geral-Estudos em Jornalismo, Ponta Grossa, vol. 6, n. 1, p. 95-111, Jan/Jun, 2019.
} 
mudança de cultura, onde os próprios funcionários estavam acostumados a fazer comunicação de governo.

Com o tempo, alteramos o enfoque do noticiário. As notícias iam para o ar segundo o seu valor informativo. (...) De vez em quando, uma chamada da Agência Brasil ganhava reprodução imediata na primeira página dos mais importantes sites jornalísticos do país" (BUCCl, 2008, p. 34).

De acordo com Bucci, em três anos, as relações se transformaram e a Agência passou a ser respeitada por jornais e fontes. A gerente da Agência Brasil em 2013, Lana Cristina, atribuiu o crescimento da credibilidade do veículo ao trabalho bem feito na cobertura de atos do governo, o que não tornaria a $\mathrm{ABr}$ "chapa-branca".

Todo o trabalho é jornalístico, inclusive você jornalisticamente informar o que o governo federal está fazendo. Não é porque você informa tudo e você é do governo federal que você relata tudo direitinho [conforme a visão do governo]. Eu acho que vem inclusive aí dessa época [o aumento da credibilidade] (CRISTINA, in NITAHARA, 2015).

Apesar de dificuldades como orçamento restrito, falta de diretriz editorial clara e ataques da grande mídia, com alegações de que o governo estaria criando um aparato de mídia governamental, a comunicação pública conseguiu avançar desde 2007, conforme relata a presidenta do Conselho Curador, Rita Freire, em artigo na revista Socicom Debate (FREIRE in LOPES, 2016, p. 45). A principal face da mudança foi a TV Brasil, que se diferenciou como uma das únicas TVs abertas a oferecer conteúdo infantil e ser uma das que mais exibe cinema nacional. No corpo funcional, o quadro foi ampliado de cerca de 800 funcionários da Radiobrás para 2.500 distribuídos entre todos os veículos da EBC e a área administrativa da empresa.

Em 2011 a EBC realizou, em parceria com a Unesco, o Seminário Internacional de Mídias Públicas - Desafios e Oportunidades para o Século 21, com debates que contribuíram para a elaboração do Manual de Jornalismo da empresa. O texto orienta dar prioridade aos direitos humanos e minorias, mostrando histórias e dando voz a quem não tem espaço na mídia comercial. Por outro lado, são vedadas a objetificação da mulher, a exploração da desgraça alheia e o sensacionalismo (BEIRÃO, 2012).

\section{Expansão da Agência Brasil}

Revista Pauta Geral-Estudos em Jornalismo, Ponta Grossa, vol. 6, n. 1, p. 95-111, Jan/Jun, 2019. 
$\mathrm{Na}$ Agência Brasil, em 2014, uma reformulação do site destaca a Central de Conteúdo, área de acesso restrito sob cadastro e senha, para descarregar fotos em alta resolução (AGUIAR E LISBOA, 2016). Segundo informações obtidas pelas autoras via Lei de Acesso à Informação (LAI), em setembro de 2018 a Central de Conteúdos da EBC somava 20.679 usuários cadastrados, entre pessoas físicas e veículos de comunicação. O sistema da EBC não identifica quem baixou conteúdo nem a resolução das fotos, segundo informações repassadas pela empresa via LAI, bem como não há controle sobre que veículos utilizam que tipo de conteúdo. Em junho de 2018 o sistema contabilizou 7.221 downloads de fotos; em julho foram 6.055 e em agosto 8.468 downloads, o que indica a importância da $\mathrm{ABr}$ como fornecedora de conteúdo.

A partir de 2012, a $\mathrm{ABr}$ envia alguns correspondentes para outros países, como Portugal, Colômbia, Estados Unidos e Dinamarca, aproveitando oportunidades conseguidas de forma particular por alguns funcionários, como curso de doutorado e acompanhamento de cônjuge em missão diplomática. No Brasil, em 2015 a cobertura foi ampliada com correspondentes em Fortaleza e Manaus, além de contar com equipes nas sedes da EBC em Brasília, Rio de Janeiro e São Paulo. A partir de 2012 também chegaram vários novos concursados na empresa, substituindo contratações feitas à época da criação no modelo de Função Comissionada que exerciam funções de pessoal concursado, como reportagem e edição de textos. Em 2013 foi retomado o serviço de língua estrangeira, com o lançamento das páginas da $\mathrm{ABr}$ em inglês e em espanhol. $A$ empresa de comunicação pública britânica (BBC), fundada em 1926, por exemplo, oferece conteúdos em mais de 40 línguas $^{7}$.

O ano de 2015 foi de avanços na discussão sobre comunicação pública na empresa e mudanças na estrutura da Agência Brasil. Na Reunião do Conselho Curador de 15 de abril, o diretor-geral, Américo Martins, que chegou à empresa com o histórico de ter trabalhado na BBC, anunciou a criação da Superintendência de Agências e Novas Mídias $^{8}$. A mudança unificou a ABr, o Portal EBC e a Radioagência, segundo Martins para melhorar a distribuição de conteúdos, e incluiu oito vagas para correspondentes no Brasil, a serem preenchidas via Processo de Seleção Interna (PSI).

\footnotetext{
7 https://www.bbc.com/aboutthebbc (acesso em 03/07/19)

8 http://www.ebc.com.br/institucional/conselho-curador/noticias/2015/04/ebc-apresentamudancas-na-agencia-brasil-e-portal-ao-conselho (acesso em 25/12/18)
}

Revista Pauta Geral-Estudos em Jornalismo, Ponta Grossa, vol. 6, n. 1, p. 95-111, Jan/Jun, 2019. 
O Conselho Curador reuniu, em agosto de 2015, especialistas e sociedade civil para discutir a autonomia da empresa. Como resultado do Seminário Modelo Institucional da EBC: balanços e perspectivas ${ }^{9}$, as propostas incluíram: diferenciação visual e estrutural da EBC Serviços, responsável pelos governamentais TV NBR e Voz do Brasil; ampliar o debate sobre comunicação pública com a sociedade e incluí-la na escolha do diretor-presidente; impor uma quarentena para ocupantes de cargos na Secretaria de Comunicação da Presidência da República (Secom) serem alocados na EBC e vice-versa; e desvincular a EBC da Secom, aparecendo propostas da empresa ir para o Ministério da Cultura, da Educação ou uma Fundação independente.

$\mathrm{Na}$ época, os funcionários criticavam a "porta-giratória" entre a EBC e a Secom, o que poderia indicar uma tendência a manter a comunicação pública sob influência governamental. Na véspera do Seminário, em 10 de agosto, o diretor-presidente da EBC, Nelson Breve, entregou uma carta ${ }^{10}$ ao Conselho Curador, informando da renúncia para assumir cargo na Secom, por "convocação" do então Ministro, Edinho Silva. À época, a EBC era vinculada à Secom.

Breve fala que seria "estratégico para acelerar o processo de fortalecimento da comunicação pública" ${ }^{11}$ ter alguém na Secom que conheça a EBC. Com isso, Américo Martins assume a presidência da empresa. Na abertura do seminário, a visão dos trabalhadores da EBC foi exposta por Priscila Kerche, integrante da Comissão de Empregados:

A EBC é um divisor de águas na comunicação do país. Esperamos que o debate aqui faça com que nasça uma empresa que cumpra o seu papel. Vimos nesses anos uma relação árdua entre a EBC e o governo, com a troca de cargos entre os dois órgãos. Acreditamos que a autonomia passa pela separação clara da EBC do poder executivo. ${ }^{12}$

A interferência do governo federal na EBC é apontada no Relatório Anual da Ouvidoria de 2015, que coloca como problemas recorrentes na Agência Brasil o uso excessivo de termos técnicos; viés tendencioso em manchetes com conteúdo político ou

\footnotetext{
9 Sistematização das contribuições:

http://www.ebc.com.br/institucional/sites/_institucional/files/documentofinalseminarioebc.pdf (acesso em 26/12/18)

10 Acervo da autora, que integrou o Conselho Curador da EBC

11 Idem

12 https://umbomconselhoebc.wordpress.com/2015/08/13/seminario-do-modeloinstitucional-da-ebc/ (acesso em 26/12/18)
}

Revista Pauta Geral-Estudos em Jornalismo, Ponta Grossa, vol. 6, n. 1, p. 95-111, Jan/Jun, 2019. 
indicadores econômicos e sociais; e matérias declaratórias de autoridades sem aprofundamento ou contextualização.

Em decorrência da confusão que existe na compreensão da diferença entre "público" e "estatal", além da proximidade geográfica às fontes oficiais de informações, particularmente em Brasília, os veículos da EBC estão vulneráveis, a priori, a serem acusados de praticar um jornalismo "chapa-branca". Quando os textos das matérias parecem ser mais justificativas do que informações e nem fontes especializadas ou alternativas são consultadas, essa impressão é reforçada (Relatório anual da Ouvidoria, 2015).

O relatório aponta também oficialismo e viés sensacionalista na cobertura de manifestações. No ano, foram recebidas 424 demandas de leitores para a Agência Brasil, sendo $40 \%$ delas reclamações, com recorrência para erros de informação e parcialidade no tratamento de temas polêmicos.

Os avanços seguiram de alguma forma. Após a realização da seleção interna para correspondentes, no início de 2016 foram enviados repórteres para Porto Alegre, Belo Horizonte, Recife e Salvador. Ao lado de Fortaleza e Manaus, foi ampliada assim a regionalização da cobertura jornalística, aprofundando a função pública da $A B r^{13}$.

\section{Crise política}

No início de 2016, com o agravamento da crise política que levou ao impedimento da presidenta Dilma Roussef e o pedido de demissão do diretor-presidente da EBC, Américo Martins, e do diretor-geral, Asdrúbal Figueiró, ambos por "motivos pessoais", os conselheiros da EBC expuseram ao ministro da Secom, Edinho Silva, na reunião do Conselho Curador do dia 24 de fevereiro ${ }^{14}$, a preocupação com a autonomia da empresa, a falta de investimento e a ingerência do governo. Edinho afirmou que a decisão de criar a EBC foi política, que o projeto ainda estava se consolidando e que havia compromisso do governo com a comunicação pública.

\footnotetext{
13 http://www.ebc.com.br/institucional/sobre-a-ebc/noticias/2016/03/agencia-brasilmonta-equipe-de-correspondentes (acesso em 06/02/19)

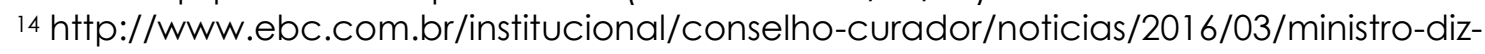
nao-ver-diferenca-entre-tv-brasil-e-nbr-conselho (acesso em 26/12/18)
}

Revista Pauta Geral-Estudos em Jornalismo, Ponta Grossa, vol. 6, n. 1, p. 95-111, Jan/Jun, 2019. 
Na reunião do Conselho Curador dos dias 18 e 19 de abril de $2016^{15}$, logo após a admissibilidade do impeachment na Câmara dos Deputados, os conselheiros disseram que a TV Brasil parecia deixar a cobertura tender demais para o lado do governo, enquanto a Agência Brasil parecia ir na direção oposta, com matérias contrárias ao governo ganhando destaque na capa do site. O diretor de jornalismo, Ricardo Melo, afirmou que a TV ficou mais de 10 horas no ar com manifestações pró-impeachment e que debatedores favoráveis ao afastamento da presidenta foram convidados, mas não compareceram. Melo afirmou que, com a cobertura ampla das manifestações contrárias ao impeachment, a EBC cumpria a função de complementar a mídia comercial, que não mostrava esses atos. Na reunião, a Ouvidoria relatou manifestações do público favoráveis à cobertura, colocando a TV Brasil como um contraponto à mídia hegemônica.

A superintendente de Agências, Denize Bacoccina, informou aos conselheiros alguns dados de visitas aos sites nos dias de manifestações contra o impeachment ${ }^{16}$ : a audiência da TV Brasil na web tinha uma média abaixo de 15 mil visitantes por dia e subiu para 37 mil no dia 18 de março, 55 mil em 31 de março, 30 mil em 11 de abril, chegando a 578 mil na votação da admissibilidade do impeachment na Câmara dos Deputados no dia 17 de abril. No Portal, a média fica abaixo de 70 mil e subiu para 119 mil no dia da votação do parecer do impeachment na comissão e 730 mil na votação no plenário da Câmara. Na Agência, a média fica na faixa de 70 mil em dias de semana e abaixo de 40 mil nos fins de semana. Entre março e abril, o pico foi em 17 de março, com 161 mil visitantes únicos. No dia da votação na câmara foram 99 mil acessos e naquele mês de março, a Agência registrou 1,5 milhão de visitantes únicos, o dobro de março de 2015.

O Conselho Curador e os funcionários temiam que a cobertura tendendo para uma defesa do governo petista, principalmente por parte dos comentaristas, levasse a uma condenação da empresa em caso de concretização do impedimento de Dilma, com o novo governo se sentindo no direito de interferir nos veículos públicos (FREIRE in LOPES, 2016, pp. 49 e 50).

A EBC acabava de sair de um quadro de instabilidade iniciado alguns meses antes, com o inesperado pedido de exoneração pelo então presidente da empresa, Américo Martins. Especulações sobre os

\footnotetext{
15 https://umbomconselhoebc.wordpress.com/2016/04/26/conselho-curador-debatecobertura-da-crise-politica-pelo-sistema-ebc/(acesso em 06/01/19)

16 Idem
}

Revista Pauta Geral-Estudos em Jornalismo, Ponta Grossa, vol. 6, n. 1, p. 95-111, Jan/Jun, 2019. 
motivos, atribuídos pela imprensa a intervenções indevidas do governo, e a demora na nomeação de substituto, geraram tensões e desconfiança. O Conselho Curador precisou lidar com aquela fase, chamando o governo a dar explicações, invocando o cumprimento do Plano de Trabalho Anual, ainda sob ajustes, e cobrando as providências para uma transição rápida (FREIRE in LOPES 2016, p. 54).

Após a votação no Senado, em 12 de maio, que aprovou a abertura do processo e afastou Dilma da presidência temporariamente, no dia 17 de maio o presidente interino Michel Temer exonera ${ }^{17}$ o presidente da EBC, Ricardo Melo, que havia sido empossado no dia 10 de maio ${ }^{18}$, e nomeia Laerte Rímoli. Porém, como a lei da EBC garantia o mandato de quatro anos, Melo conseguiu uma liminar no Supremo Tribunal Federal e retornou ao cargo em 03 de junho ${ }^{19}$.

Nesse meio tempo, as mudanças na empresa foram devastadoras. Do dia que Rímoli tomou posse, em 20 de maio ${ }^{20}$, até o dia 10 de junho, foram publicadas mais de 50 portarias de dispensa de cargo. Entre os comentaristas e apresentadores contratados como pessoa jurídica que tiveram seus contratos rompidos estão Luis Nassif, Paulo Moreira Leite, Emir Sader, Tereza Cruvinel e Sidney Rezende. Programas da TV Brasil foram cancelados sem aviso ao público (FREIRE in LOPES 2016, p. 56).

$\mathrm{Na}$ Agência Brasil, os editores foram orientados a não utilizar mais o termo presidenta ${ }^{21}$, padrão adotado em 2011 com a posse de Dilma. Somente após deliberação do Comitê Editorial ${ }^{22}$, instituído às pressas com o retorno de Melo, ficou decidido que cada pessoa seria identificada conforme sua preferência. Também foi perceptível a edição cuidadosa das fotografias e matérias relacionadas à presidenta deposta, não dando

\footnotetext{
17 http://agenciabrasil.ebc.com.br/politica/noticia/2016-05/presidente-da-ebc-eexonerado-e-recorre-justica-para-garantia-do-mandato (acesso em 27/12/18) $18 \mathrm{http}: / / a g e n c i a b r a s i l . e b c . c o m . b r / g e r a l / n o t i c i a / 2016-05 /$ ricardo-melo-assumepresidencia-da-ebc (acesso em 27/12/18) 19 http://agenciabrasil.ebc.com.br/geral/noticia/2016-06/ricardo-melo-reassumepresidencia-da-ebc (acesso em 27/12/18)

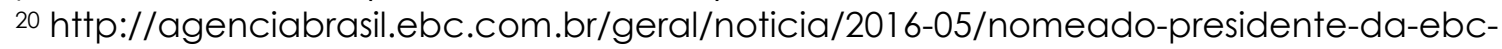
laerte-rimoli-diz-que-devolvera-empresa-sociedade (acesso em 27/12/18)

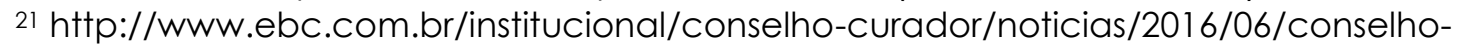
orienta-ebc-o-uso-do-termo-presidenta (acesso em 28/12/18)

22 http://www.ebc.com.br/institucional/sites/_institucional/files/atoms/files/portaria__presi_no_460_-_reformulacao_do_comite_editorial_de_jornalismo.pdf (acesso em $28 / 12 / 18)$
}

Revista Pauta Geral-Estudos em Jornalismo, Ponta Grossa, vol. 6, n. 1, p. 95-111, Jan/Jun, 2019. 
destaque ao apoio popular que ela recebia. Galerias de fotos de manifestações não foram publicadas e atos foram reduzidos a anexos de outros textos ${ }^{23}$.

Com o impedimento definitivo de Dilma, em 31 de agosto, no dia $1^{\circ}$ de setembro de 2016 é editada a Medida Provisória $744^{24}$, que desfigura o caráter público da $\mathrm{EBC}^{25}$ com a retirada do mandato do diretor-presidente e a extinção o Conselho Curador, mas mantém no papel os princípios e objetivos da comunicação pública. Com isso, o ministro do STF Dias Toffoli suspende a liminar concedida a Melo ${ }^{26}$, por perda de objeto, e Rímoli reassume a presidência da EBC.

\section{Retrocessos}

A MP 744 foi convertida na lei no $13.417^{27}$ e a Câmara dos Deputados manteve os vetos presidenciais às mudanças que o próprio Congresso aprovou, na tentativa de salvar na lei um pouco do que restava de comunicação pública na EBC. Havia sido inserida uma sabatina no Senado para aprovar o nome do diretor-presidente e estabelecido um Comitê Editorial consultivo e deliberativo, para substituir o Conselho Curador, com funções como debater os planos editoriais e conteúdos da empresa. O veto retirou a sabatina e deixou o Comitê com funções figurativas ${ }^{28}$. Mas, até o momento o órgão não foi implementado. Além disso, a empresa desmobilizou na mesma época o Comitê Editorial interno, que era composto por jornalistas da EBC para discutir a cobertura jornalística dos veículos públicos.

Em junho, Alberto Coura assume a Gerência Executiva e Roberto Cordeiro a Gerência de Redação em Brasília. Sob a gestão Alberto-Roberto, a Agência Brasil viveu

\footnotetext{
$23 \mathrm{http} / / / a g e n c i a b r a s i l . e b c . c o m . b r / p o l i t i c a / n o t i c i a / 2016-06 / d i l m a-c o n d e n a-c u l t u r a-d o-$ estupro-e-segregacao-social-em-ato-de-mulheres-no e http://agenciabrasil.ebc.com.br/politica/noticia/2016-06/planalto-recomenda-que-dilmause-avioes-da-fab-apenas-para-ir-porto-alegre (acesso em 29/06/19)

24 http://www.planalto.gov.br/ccivil_03/_Ato2015-2018/2016/Mpv/mpv744.htm (acesso em 29/06/19)

${ }_{25}$ Manifestações contrárias à MP 744: http://pfdc.pgr.mpf.mp.br/informativos/edicoes-

2016/outubro/pfdc-defende-inconstitucionalidade-de-mp-que-alterou-a-ebc/ (acesso em 20/04/19) e https://nacoesunidas.org/brasil-relatores-da-onu-e-oea-sobre-liberdade-deexpressao-alertam-para-interferencias-na-ebc-e-na-cgu/ (acesso em 20/04/19)

26 http://agenciabrasil.ebc.com.br/geral/noticia/2016-09/toffoli-cassa-liminar-e-ricardomelo-deixa-presidencia-da-ebc-rimoli-reassume (acesso em 28/12/18)

27 https://www2.camara.leg.br/legin/fed/lei/2017/lei-13417-1-marco-2017-784396publicacaooriginal-152055-pl.html (acesso em 29/06/19)

$28 \mathrm{https}$ //umbomconselhoebc.wordpress.com/2017/03/20/uma-empresa-publica-aservico-do-governo/ (acesso em 29/06/19)
}

Revista Pauta Geral-Estudos em Jornalismo, Ponta Grossa, vol. 6, n. 1, p. 95-111, Jan/Jun, 2019. 
meses de censura nunca vista antes em momentos de democracia e na comunicação pública do país. Cordeiro era da assessoria do Ministério da Defesa e na $\mathrm{ABr}$ pareceu exercer a mesma função em sua gestão, em meio a decretos de Garantia da Lei e da Ordem (GLO) e a intervenção federal no Rio de Janeiro. Um dossiê sobre censura foi feito em 2018 pelos funcionários (tratado adiante). As perseguições se aprofundaram e foram denunciadas pelos empregados ${ }^{29}$.

Entre os relatos há a troca arbitrária dos setoristas e de setor dentro da empresa e o fim do projeto dos correspondentes ${ }^{30}$. Essas medidas enxugaram os recursos humanos da $\mathrm{ABr}$. De todos os repórteres que retornaram, apenas um permaneceu na Agência Brasil, no Rio de Janeiro. Durante o ano de 2017, cerca de 40 profissionais da EBC se desligaram da empresa, muitos por terem negados seus pedidos de licenças, mesmo que não remuneradas ${ }^{31}$. A ABr perdeu uma repórter e uma editora ${ }^{32}$.

No Relatório Anual da Ouvidoria de 2017, o último da ouvidora independente Joseti Marques, que deixou a EBC em março de 2018 com o fim do seu mandato, é apontado um problema na própria Ouvidoria e no monitoramento do conteúdo da empresa pública:

A substituição dos adjuntos por decisão unilateral da alta gestão da empresa causou uma descontinuidade no serviço, porque foram indicadas pessoas inexperientes na observação crítica das produções e, naturalmente, tiveram e ainda têm dificuldades de realizar a tarefa (Relatório Anual da Ouvidoria 2017).

Entre os problemas apontados na $\mathrm{ABr}$ pela Ouvidoria está o aprofundamento da abordagem oficialista das notícias, borrando os limites entre comunicação pública, estatal e institucional da EBC. Segundo a Ouvidoria, houve casos de destaque para falas do presidente e ministros no lugar da notícia em si, com declarações sem contextualização nem contraponto, beirando o proselitismo. Nas matérias que tratam de denúncias contra o governo, o fato praticamente não aparece, bem como a Agência aparenta

\footnotetext{
$29 \mathrm{http}: / / w w w . s j p d f . o r g . b r / n o t i c i a s-t e s t e / 3623-e n t i d a d e s-r e p u d i a m-o f e n s a s-d e-g e r e n t e-$ executivo-da-agencia-brasil (acesso em 06/02/19) e http://www.sjpdf.org.br/noticiasteste/3392-ebc-desrespeito-com-os-profissionais-e-desmonte-da-comunicacao-publica (acesso em 06/02/19)

30 Idem

31 Relatos anônimos à autora

32 Portarias 2017: http://www.ebc.com.br/institucional/lei-de-acesso-ainformacao/portarias-2017 (acesso em 29/06/19)
}

Revista Pauta Geral-Estudos em Jornalismo, Ponta Grossa, vol. 6, n. 1, p. 95-111, Jan/Jun, 2019. 
constrangimento em noticiar assuntos desfavoráveis ao governo. Das 2.909 manifestações recebidas no ano, 105 foram referentes à Agência Brasil, ou 3,6\%.

O ano de 2018 começou com mais tensão e desrespeito aos princípios do jornalismo público. Foi denunciado que um contrato entre a EBC e a Agência Nacional de Águas (ANA) previa o pagamento pela ANA de $\mathrm{R} \$ 1,8$ milhão para cobertura jornalística a ser feita pelos veículos públicos no Fórum Mundial das Águas, que ocorreu em março em Brasília $^{33}$. Diante da recusa da empresa em sinalizar nas matérias que se tratava de um contrato e das pautas direcionadas, muitos repórteres pediram para não assinar os textos.

O nível da censura chegou a barrar posições críticas à empresas patrocinadoras do evento e atingiu o ápice com a demissão do chefe de Redação da Agência Brasil, em São Paulo, o jornalista Décio Trujilo, há poucas semanas, por pressão do governo de São Paulo, depois de matéria que desagradou, sobre problemas no abastecimento em SP. Vale lembrar que, enquanto a Agência Brasil publica cerca de 10 matérias por dia sobre o Fórum Mundial da Água, devido a sobrecarga dessa cobertura paga, a EBC, pela primeira vez desde sua criação, deixou de cobrir o Fórum Social Mundial e mal vem cobrindo o Fórum Mundial Alternativo da Água, que reúne ambientalistas e especialistas críticos ao fórum oficial. ${ }^{34}$

A portaria de demissão de Trujilo saiu no dia 28 de fevereiro. Enquanto isso, a EBC era alvo de mais escândalos. O Diretor de Jornalismo, Lourival Macedo, aderiu ao Plano de Demissão Voluntária (PDV), mas continuou no cargo de diretor, assim como Luiz Antonio Ferreira, Diretor de Finanças. Saíram da Agência Brasil no PDV dois repórteres, um editor, a coordenadora de Língua Estrangeira e uma repórter fotográfica. Para aderir era preciso ter pelo menos 10 anos de casa e 53 de idade.

Roberto Cordeiro é exonerado da gerência da $\mathrm{ABr}$ em Brasília em 27/03/18, após a censura de matérias sobre a execução da vereadora carioca Marielle Franco ter sido noticiada pela imprensa ${ }^{35}$. Em abril foi a vez de Beto Coura deixar o cargo de gerente

33 http://www.sjpdf.org.br/noticias-teste/3597-ataque-ao-jornalismo-publico-no-contratoda-ebc-para-cobertura-do-forum-da-agua (acesso em 06/02/19) e http://www.sjpdf.org.br/noticias-teste/3610-nota-o-jornalismo-sequestrado-na-ebc (acesso em 06/02/19)

34 Idem

$35 \mathrm{https}$ //painel.blogfolha.vol.com.br/2018/03/20/ebc-manda-reduzir-cobertura-sobremarielle-para-evitar-exploracao-politica/ (acesso em 14/02/19),

https://www.revistaforum.com.br/chefia-ebc-censura-marielle-franco/ (acesso em 14/02/19), https://www.pragmatismopolitico.com.br/2018/03/censura-do-caso-mariellena-ebc.html (acesso em 14/02/19), https://jornalggn.com.br/midia/jornalista-da-ebc-sao-

Revista Pauta Geral-Estudos em Jornalismo, Ponta Grossa, vol. 6, n. 1, p. 95-111, Jan/Jun, 2019. 
executivo. Renata Giraldi, jornalista com experiência em grandes jornais, assume a Gerência de Redação em Brasília. Em maio Mara Bergamaschi, também "do mercado", assume a gerência executiva. Porém, os caminhos da comunicação pública continuaram tortuosos e os empregados e entidades representativas denunciaram ${ }^{36}$ uso político da Agência Brasil, com a publicação de matérias especulativas e tendenciosas ${ }^{37}$, o que é proibido pelo manual de jornalismo da empresa (BEIRÃO, 2012, p. 23).

Em reunião do Conselho de Administração no dia 21 de abril, foi aprovado um realinhamento da EBC em que são definidas como estratégia "fortalecer a comunicação de Estado" e a "adaptação da Agência Brasil para a comunicação de Estado", que passaria a "comunicar apenas notícias de Estado". As entidades denunciaram a ilegalidade da medida ${ }^{38}$, já que a comunicação pública é prevista na Constituição. $A$ ata da reunião ${ }^{39}$ traz apenas uma breve descrição das mudanças, com o texto que se refere à Agência Brasil ficando com a seguinte redação: "adaptação processual e de plataforma para que a Agência Brasil aprimore a comunicação de notícias de Estado e da sociedade".

Em maio o presidente Laerte Rímoli deixa a empresa ${ }^{40}$ e é acusado pelas entidades representativas dos funcionários de manipular os dados sobre as contas da

proibidos-de-cobrir-protestos-em-memoria-de-marielle/ (acesso em 14/02/19),

http://www.srzd.com/brasil/censura-ebc-acusada-vetar-cobertura-caso-marielle-franco/ (acesso em 14/02/19), https://www.redebrasilatual.com.br/politica/2018/03/jornalistas-daebc-protestam-contra-censura-no-caso-marielle (acesso em 14/02/19) e https://portal.comunique-se.com.br/censura-sindicato-denuncia-veto-da-ebc-nacobertura-do-caso-marielle-franco/ (acesso em 14/02/19)

36 http://www.sjpdf.org.br/noticias-teste/3669-entidades-publicam-nota-de-repudio-sobreuso-politico-da-agencia-brasil (acesso em 06/02/19)

$37 \mathrm{http}$ ://agenciabrasil.ebc.com.br/politica/noticia/2018-06/ministro-da-cultura-deve-pedirdemissao (acesso em 20/04/19), http://agenciabrasil.ebc.com.br/politica/noticia/201806/temer-ainda-estuda-nome-para-presidencia-da-petrobras (acesso em 20/04/19) e http://agenciabrasil.ebc.com.br/economia/noticia/2018-06/oit-reforma-trabalhistarespeita-negociacao-coletiva-de-trabalhadores (acesso em 20/04/19) 38 http://www.sjpdf.org.br/noticias-teste/3634-de-forma-ilegal-governo-e-direcao-da-ebcquerem-tornar-agencia-brasil-e-tv-brasil-orgaos-governamentais-e-liquidar-de-vez-acomunicacao-publica (acesso em 06/02/19) e http://www.sjpdf.org.br/noticias-teste/3636trabalhadores-dizem-nao-a-tentativa-da-direcao-da-ebc-e-do-governo-federal-deproibir-jornalismo-e-liquidar-a-comunicacao-publica-na-empresa (acesso em 06/02/19) 39http://www.ebc.com.br/institucional/sites/_institucional/files/atoms/files/ata_4a_reuniao_ ordinaria_23-04-2018_1.pdf (acesso em 06/02/19)

$40 \mathrm{http}: / /$ www.valor.com.br/empresas/5495181/sob-comando-de-rimoli-ebc-conseguezerar-deficit (acesso em 06/02/19)

Revista Pauta Geral-Estudos em Jornalismo, Ponta Grossa, vol. 6, n. 1, p. 95-111, Jan/Jun, 2019. 
$\mathrm{EBC}^{41}$. Assume no lugar dele Alexandre Parola. Estevão Damázio, que estava apresentando o programa de entrevistas Diálogo Brasil, na TV Brasil, é nomeado Diretor de Jornalismo.

No meio do ano, as entidades dos empregados produziram um dossiê sobre os casos de censura e governismo na cobertura jornalística da $\mathrm{EBC}^{42}$. Com a colaboração dos trabalhadores, foram relatadas 61 denúncias, sendo 29 na Agência Brasil. A maioria trata de fatos ou opiniões contrárias ao governo Michel Temer, além de análise de especialistas em matérias como as que abordavam o uso das forças armadas na segurança, a intervenção federal no Rio de Janeiro, a política de preços da Petrobras e, com destaque, o assassinato da vereadora Marielle Franco.

Um dos gerentes da Agência Brasil, Alberto Coura, escreveu um e-mail dizendo que a cobertura do Rio de Janeiro estava cansativa e repetitiva quando esta era a notícia do momento em todos os veículos de comunicação da cidade, do país e com importantes repercussões internacionais. Outro gerente, Roberto Cordeiro, foi mais explícito e escreveu, em e-mail que vazou, que a cobertura de homenagens à vereadora só servia para dar palanque ao $\mathrm{PSOL}^{43}$.

Em dezembro, um novo PDV, desta vez aberto a profissionais de toda as idades e sem limite de tempo de casa, tem mais adesões na $\mathrm{ABr}$ : dois editores, cinco repórteres e dois tradutores. Com isso, a Agência ficou com 13 editores em Brasília, além de quatro coordenadores, 20 repórteres e sete repórteres fotográficos; dez repórteres e três repórteres fotográficos no Rio de Janeiro; e oito repórteres e uma repórter fotográfica em São Paulo. E nenhum correspondente em outros estados ou no exterior.

O relatório anual da Ouvidoria em $2018^{44}$ mudou totalmente de foco e formato. Após a saída de Joseti Marques, assumiu o cargo interinamente em abril Edit Silva, indicada da direção da empresa, e posteriormente Cristiane Samarco, em 4 de setembro, que era diretora-geral, tendo como ouvidor adjunto o ex-diretor de jornalismo Lourival

\footnotetext{
${ }^{41} \mathrm{http} / / / w w w . s j p d f . o r g . b r / n o t i c i a s-t e s t e / 3641$-artigo-rimoli-deixa-a-ebc-e-manipula-dadospara-encobrir-desastre-de-sua-gestao (acesso em 06/02/19)

42 http://www.sjpdf.org.br/noticias-teste/3722-trabalhadores-denunciam-mais-de-60-casosde-censura-e-governismo-na-ebc (acesso em 06/02/19)

43 Idem

44http://www.ebc.com.br/institucional/sites/_institucional/files/atoms/files/relatorio_da_ouvi doria_anual_2018_1.pdf (acesso em 15/02/19)
}

Revista Pauta Geral-Estudos em Jornalismo, Ponta Grossa, vol. 6, n. 1, p. 95-111, Jan/Jun, 2019. 
Macedo. Ex-integrantes do Conselho Curador denunciaram a manobra como o fim do último espaço de participação e controle social da EBC ${ }^{45}$.

O relatório traz como propaganda diversos feitos da EBC durante o ano, com foco nos serviços governamentais, incluindo a transmissão da posse do presidente Jair Bolsonaro no dia $1^{\circ}$ de janeiro de 2019, a cobertura do Fórum Mundial da Água e uma entrevista com o presidente Temer. Sobre a Agência Brasil, a Ouvidoria apontou que o site teve 39,8 milhões de visualizações em 2018, mas que a audiência real é muito maior "em razão do sistema de captura automática dos conteúdos EBC pelos Portais Terra e UOL", além de afirmar que "todos os grandes jornais de alcance nacional - como $O$ Estado de S. Paulo, Folha de S. Paulo, O Globo e o Correio Braziliense - utilizam-se do conteúdo da Agência e dão crédito nos impressos e online".

Como sugestão, o órgão considera que, por ter a maior audiência e prestígio da EBC, a Agência deve ajudar a fomentar audiência para os demais veículos, inclusive os governamentais. Nota-se nesse relatório que a Ouvidoria deixou de considerar a comunicação pública como foco prioritário da EBC e a comunicação governamental como uma prestação de serviço da empresa, como de fato é, passando a não diferenciar os dois tipos de conteúdo.

\section{Conclusões e perspectivas}

Os acontecimentos em sequência indicando uma política de estrangulamento do espaço que configurava a Agência Brasil como um lugar de exercício da comunicação pública continuaram. Em 2019, após algumas trocas de chefias na $\mathrm{ABr}$, em abril assumiu a Gerência Executiva Narjara Carvalho e Sirlei Batista ficou como diretora de Jornalismo. Ambas eram dos quadros da NBR, o braço governamental da EBC, o que indica a tendência de cobertura jornalística que a empresa assumiu. Após o presidente Jair Bolsonaro autorizar a celebração do 31 de março de $1964^{46}$, veículos da EBC modularam expressões utilizadas ${ }^{47}$ para se referir ao golpe militar e a ditadura que durou 21 anos no

\footnotetext{
45 https://conselhocurador.ciranda.net/blog/o-fim-do-ultimo-espaco-de-participacao-econtrole-social-da-ebc (acesso em 15/02/19)

46 http://agenciabrasil.ebc.com.br/politica/noticia/2019-03/bolsonaro-autoriza-

celebracao-do-31-de-marco-de1964 (acesso em 09/04/19)

47 http://agenciabrasil.ebc.com.br/politica/noticia/2019-03/para-bolsonaro-nao-houve-

ditadura-no-brasil (acesso em 09/04/19)
}

Revista Pauta Geral-Estudos em Jornalismo, Ponta Grossa, vol. 6, n. 1, p. 95-111, Jan/Jun, 2019. 
Brasil. A interferência gerou manifestações ${ }^{48}$, com repercussão na mídia ${ }^{49}$ e entidades de defesa dos direitos humanos e da liberdade de expressão ${ }^{50}$.

A reestruturação da EBC constou na lista de prioridades para os 100 primeiros dias do governo, o que foi feito, em parte, com a unificação da TV Brasil com a TV NBR, em abril, o que acabou com a complementariedade prevista na constituição entre os sistemas público, privado e governamental de comunicação.

Em meio à crise política que tomou conta do Brasil a partir de 2015, funcionários da EBC e o Conselho Curador discutiam meios de consolidar o projeto da comunicação pública no país, que estava então se fortalecendo. Porém, o turbilhão de acontecimentos que se sucederam paralisou o processo e tem recolocado a EBC em uma posição de comunicação governamental e sem a participação da sociedade.

O exemplo da Agência Brasil confirma a dificuldade de estabelecer-se uma voz representativa da sociedade independente da estrutura formal do Estado, e esta tendência é tão mais aguda quanto menos democrática é a conjuntura política governamental.

\section{Referências}

AGUIAR, Pedro; LISBOA; Juliana. Da Agência Nacional à Agência Brasil: o jornalismo de agências e o Estado brasileiro (1937-2016). 6ํㅡㄹ Encontro Regional Sul de História da Mídia. Alcar Sul: junho 2016.

BEIRÃO, Nereide (Presidente da Comissão); ACHILIS, Antonio (Redação). Manual de Jornalismo da EBC - Somente a Verdade. Brasília: junho de 2012.

BUCCI, Eugênio. Em Brasília, 19 horas - A guerra entre a chapa-branca e o direito à informação no primeiro governo Lula. Rio de Janeiro: Editora Record, 2008.

BUCCI, Eugênio; CHIARETTI, Marco; FIORINI, Ana Maria. Indicadores de Qualidade nas Emissoras Públicas - Uma análise Contemporânea. Série Debates $\mathrm{Cl}$ ํำ10. Brasil: Representação da Unesco, junho de 2012.

LOPES, Ruy Sardinha (Organização). (2016). SOCICOM Debate - A comunicação em questão: crise na EBC. $2^{\mathrm{a}}$ edição. São Paulo: SOCICOM, 2016.

\footnotetext{
$48 \mathrm{http}: / /$ www.sjsp.org.br/noticias/ebc-censura-golpe-e-ditadura-em-reportagens-01 d0 (acesso em 09/04/19)

49 https://veja.abril.com.br/politica/empregados-da-ebc-denunciam-censura-as-palavrasgolpe-e-ditadura/ e https://www.redebrasilatual.com.br/politica/2019/03/ebc-sofrecensura-em-cobertura-sobre-o-golpe-de-1964-e-ditadura (acesso em 09/04/19)

$50 \mathrm{https}: / /$ vladimirherzog.org/nota-publica-em-nome-da-memoria-da-verdade-e-dajustica/ (acesso em 09/04/19)
}

Revista Pauta Geral-Estudos em Jornalismo, Ponta Grossa, vol. 6, n. 1, p. 95-111, Jan/Jun, 2019. 
NITAHARA, Akemi. A Agência Brasil como fonte de informação para outros veículos on-line. I Encontro de Pesquisadores da EBC. Rio de Janeiro: junho 2015.

Portarias da EBC (http://www.ebc.com.br/institucional/node/2261).

Relatórios da Ouvidoria anuais 2015, 2016, 2017 e 2018

(http://www.ebc.com.br/institucional/ouvidoria/relatorios-anos-anteriores).

Recebido em: 08/03/2019.

Publicado em: 23/07/2019.

Revista Pauta Geral-Estudos em Jornalismo, Ponta Grossa, vol. 6, n. 1, p. 95-111, Jan/Jun, 2019. 